\title{
Contribution of the Potassium-Chloride Cotransporter KCC2 to the Strength of Inhibition in the Neonatal Rodent Spinal Cord In Vitro
}

\author{
Florian Gackière and Laurent Vinay \\ Institut de Neurosciences de la Timone, UMR 7289, CNRS, Aix Marseille Université, 13385 Marseille cx 5, France
}

\begin{abstract}
In healthy mature motoneurons (MNs), KCC2 cotransporters maintain the intracellular chloride concentration at low levels, a prerequisite for postsynaptic inhibition mediated by GABA and glycine. KCC2 expression in lumbar MNs is reduced after spinal cord injury (SCI) resulting in a depolarizing shift of the chloride equilibrium potential. Despite modeling studies indicating that such a downregulation of KCC2 function would reduce the strength of postsynaptic inhibition, physiological evidence is still lacking. The present study aimed at investigating the functional impact of a modification of KCC2 function. We focused on a well characterized disynaptic inhibitory pathway responsible for reciprocal inhibition between antagonistic muscles. We performed in vitro extracellular recordings on spinal cords isolated from rodents at the end of the first postnatal week. Genetic reduction of KCC2 expression, pharmacological blockade of KCC2, as well as SCI-induced downregulation of KCC2 all resulted in a reduction of the strength of reciprocal inhibition. We then tried to restore endogenous inhibition after SCI by means of zinc ions that have been shown to boost KCC2 function in other models. Zinc chloride indeed hyperpolarized the chloride equilibrium potential in MNs and increased reciprocal inhibition after neonatal SCI. This study demonstrates that the level of KCC2 function sets the strength of postsynaptic inhibition and suggests that the downregulation of KCC2 after SCI likely contributes to the high occurrence of flexor- extensor cocontractions in SCI patients.
\end{abstract}

Key words: chloride homeostasis; KCC2; reciprocal inhibition; spasticity; zinc

\section{Introduction}

The proper operation of neuronal networks relies on a balance between excitation and inhibition. A perturbation of this balance in pathological conditions such as after spinal cord injury (SCI) leads to spasticity, a syndrome that is characterized by involuntary muscular spasms, tendon jerks, and an increased muscle resistance to passive stretch (Lance, 1980). Most SCI patients suffer from spasticity 1 year after injury (Crone et al., 2000, 2003; Morita et al., 2001). It is widely accepted that at least two mechanisms in the spinal cord below the lesion contribute to this disorder: an increased excitability of motoneurons (MNs; (Li et al., 2004; Boulenguez and Vinay, 2009) and a reduction of inhibition (known as disinhibition; Boorman et al., 1996; Mazzocchio and Rossi, 1997; Katz, 1999). Disinhibition was recently suggested as being caused by a reduced expression of the potassium $\left(\mathrm{K}^{+}\right)$-chloride $\left(\mathrm{Cl}^{-}\right)$cotransporters $\mathrm{KCC} 2$ in the membrane of MNs thereby increasing the intracellular concentration

Received April 24, 2014; revised Feb. 16, 2015; accepted Feb. 26, 2015.

Author contributions: F.G. and L.V. designed research; F.G. performed research; F.G. analyzed data; F.G. and L.V. wrote the paper.

This work was supported by the International Spinal Research Trust and the Agence Nationale pour la Recherche. We thank Cécile Brocard and Sylvie Liabeuf for their technical assistance, and all team members for helpful discussion of the data presented here.

The authors declare no competing financial interests.

Correspondence should be addressed to Dr Laurent Vinay, Institut de Neurosciences de la Timone, Campus santé Timone, 27, boulevard Jean Moulin, 13385 Marseille cx 5, France. E-mail: laurent.vinay@univ-amu.fr.

DOI:10.1523/JNEUROSCI.1674-14.2015

Copyright $\odot 2015$ the authors $\quad 0270-6474 / 15 / 355307-10 \$ 15.00 / 0$ of chloride ions and reversing the effect of IPSPs from hyperpolarization to depolarization (Jean-Xavier et al., 2006; Boulenguez et al., 2010; Bos et al., 2013). For instance, immunohistochemical experiments indeed revealed a reduction of KCC2 expression in MNs 4-6 d after spinal cord transection performed on the day of birth. This was associated with a depolarization of the reversal potential of IPSPs $\left(\mathrm{E}_{\text {IPSPs }}\right.$ ) in lumbar MNs compared with noninjured animals (Jean-Xavier et al., 2006; Bos et al., 2013).

An important issue is to determine the functional consequences of a downregulation of KCC2 expression that induces a $\sim 10-15 \mathrm{mV}$ depolarizing shift of $\mathrm{E}_{\text {IPSPs }}$ in SCI rats (Jean-Xavier et al., 2006; Boulenguez et al., 2010; Bos et al., 2013). In different areas of the CNS including the spinal cord, small depolarizing IPSPs can facilitate action potential firing when they are combined with subthreshold excitatory inputs (Chen et al., 1996; Gao and van den Pol, 2001; Gulledge and Stuart, 2003; Stein and Nicoll, 2003; Jean-Xavier et al., 2007). In addition, modeling studies have suggested that a depolarizing shift of KCC2 increases the cell excitability (Prescott et al., 2006; Doyon et al., 2011). Despite these findings, the functional impact of a disruption of chloride homeostasis on sensory-motor function is still unknown keeping the question of whether SCI-induced KCC2 deficiency is sufficient to cause a motor dysfunction open.

To answer this question, we focused on a well characterized inhibitory reflex pathway through which group Ia afferents provide inhibition of MNs innervating antagonistic muscles (Hultborn and Udo, 1972; Jankowska, 1992). This reciprocal disynaptic inhibition 
is mediated by glycinergic interneurons (INs) termed Ia inhibitory INs (Curtis et al., 1968; Jankowska and Lindström, 1972) and is functional at birth in mice (Sonner and Ladle, 2013). Using this model in vitro we demonstrate that modulating KCC2 function markedly affects the strength of inhibition.

\section{Materials and Methods}

Animals and preparations. The mammalian KCC2 gene (Slc12a5) generates two alternatively spliced isoforms KCC2a and KCC2b, which differ from each other in their N-terminal part (Uvarov et al., 2007). Some experiments $(n=15)$ were performed on neonatal transgenic mice with a targeted disruption of KCC2 exon 1b, which lack KCC2b but retain KCC2a mRNA. The KCC2 mouse strain (C57BL/6 genetic background) was provided by E. Delpire (Vanderbilt University School of Medicine, Nashville, TN) (Woo et al., 2002). At the end of the first postnatal week, $\mathrm{KCC}^{-1-}\left(\operatorname{Slc} 12 a 5^{-1-}\right)$ mice express $\sim 21 \%$ of KCC2 compared with the wild-type $\mathrm{KCC}^{+/+}\left(\right.$Slc12a5 $\left.5^{+/+}\right)$mice (Stil et al., 2011). In addition to these mice (home bred, both sexes), we used neonatal Wistar rats (originally collected from Janvier Laboratories and then home bred; both sexes; $n=89$ ) which were all housed in a temperature-controlled animalcare facility with a $12 \mathrm{~h} \mathrm{light/dark} \mathrm{cycle.} \mathrm{The} \mathrm{postnatal} \mathrm{ages} \mathrm{of} \mathrm{animals}$ were measured in terms of days after birth. We made all efforts to minimize the number of animals used and animal suffering. All surgical and experimental procedures were in accordance with the French regulations (Ministry of Food, Agriculture and Fisheries; Division of Health and Protection of Animals) and were approved by the local ethical committee (Comité d'éthique en Neurosciences, Institut de Neurosciences de la Timone, Marseille, №71; A9/01 13).

Genotyping. Briefly, tail fragments were frozen and kept at $-80^{\circ} \mathrm{C}$. Purification of DNA was performed after overnight incubation in a lysis buffer. Control and mutant fragments of $k c c 2$ gene were amplified by PCR by using the same forward primer ( 5 ' -AGCGTGTGTCCGTGTGCGAGTG- $\left.3^{\prime}\right)$ and different reverse primers for the control and the mutant genes ( $5^{\prime}$-CCGTCCTCGCAGTCCGTCAGGTTG- $3^{\prime}$ and 5' -CCAGAGGCCACTTGTGTAGCGC-3', respectively). Both sets of oligonucleotides generate a $0.2 \mathrm{~kb}$ PCR product. Note that researchers were blinded to genotype of the animals throughout in vitro experiments and data analysis.

Surgical procedure: neonatal SCI. Rats were deeply anesthetized by hypothermia at birth. A dorsal midline skin incision was made over the thoracic vertebra and the overlying fascia and muscles were retracted to expose the dorsal surface of the vertebrae. After a partial laminectomy, the spinal cord was completely transected at the T8 thoracic level with scissors. The lesion cavity was then filled with sterile absorbable local hemostat Surgicoll (Medical Biomaterial Products). The skin incision was closed with sutures (PDSII 6.0, Ethicon; Johnson and Johnson) and covered by Steri-Strips ( $3 \mathrm{M}$ Health Care). The whole surgical procedure took $<10 \mathrm{~min}$ after anesthesia. Sham-operated rats were treated in the same way except the spinal cord transection. Following surgery, the neonates recovered $45 \mathrm{~min}$ in a warm environment maintaining the temperature at $35 \pm 1{ }^{\circ} \mathrm{C}$. Wounds were then cleaned and rats were kept in a warm environment for $40 \mathrm{~min}$ before returning to the nest.

Spinal cord preparations. Spinal cords isolated from neonatal animals were dissected together with spinal roots. Briefly, after decapitation and evisceration, the spinal cord was exposed by dorsal laminectomy and acute removal of the dura in a cold artificial CSF (ACSF; containing the following (in mM): $130 \mathrm{NaCl}, 4 \mathrm{KCl}, 3.75 \mathrm{CaCl}_{2}, 1.3 \mathrm{MgSO}_{4}, 0.58$ $\mathrm{NaH}_{2} \mathrm{PO}_{4}, 25 \mathrm{NaHCO}_{3}$, and 10 glucose; all compounds were from Sigma-Aldrich; oxygenated with $95 \% \mathrm{O}_{2} / 5 \% \mathrm{CO}_{2}, \mathrm{pH} 7.4$ ). By a careful inspection of the lack of continuity between the spinal stumps, we verified the completeness of the spinal cord transection for injured-rats (SCI rats, $n=23$ ). Cord, from sacral segments up to T8, was then removed from the vertebral column together with peripheral roots, notably those from the lumbar L3 and L5 segments that contain the MNs projecting to the knee extensor and flexor muscles, respectively (NicolopoulosStournaras and Iles, 1983). The preparation was then transferred to the recording chamber and allowed to recover for $1 \mathrm{~h}$ in oxygenated ACSF equilibrated at room temperature $\left(24 \pm 1^{\circ} \mathrm{C}\right)$. The isolated spinal cord preparation was pinned down, ventral side up, in sylgard (DowCorning)-covered recording chamber, and continuously perfused with the ACSF solution. All ventral (VR) and dorsal (DR) roots were also carefully pinned.

In vitro extracellular recordings. Extracellular electrophysiological signals of lumbar VR and DR responses were recorded by contact stainless steel electrodes insulated from the bath with Vaseline. Data were acquired through an AC-coupled amplifier (bandwidth: $70-3 \mathrm{kHz}$ ) and a Digidata 1440A interface using the Clampex 10.2 software (Molecular Devices).

Evaluation of reciprocal inhibition. The protocol was adapted from previous reports (Wang et al., 2008; Talpalar et al., 2011; Sonner and Ladle, 2013). Single pulses were delivered to the DR to evoke responses in the homonymous VR. We stimulated at two to three times the threshold (T) intensity that evoked an incoming volley in the DR. The current pulses ( $0.3 \mathrm{~ms}$ duration) required to elicit the maximal response varied among preparations (from 0.2 to $0.6 \mathrm{~V}$ for mice; from 0.6 to $1.2 \mathrm{~V}$ for rats). Stimulations were delivered every $20 \mathrm{~s}$ to avoid fatigue and synaptic depression described previously (Lev-Tov and Pinco, 1992). Test and conditioning stimulations were delivered to the L5 and L3 DRs, respectively. Delays between the two stimulations ranged from 0 to $40 \mathrm{~ms}$. Each delay was tested at least three times in the following way: five controls (test only) followed by five paired (conditioning + test) stimulations. The order in which delays were tested was randomized from series to series to prevent possible order-dependent effects. Data analysis was performed offline and consisted in measuring the peak-to-antipeak amplitude of the L5 monosynaptic reflex (Clampfit 10.2 software). To consider only the monosynaptic component, we restricted measurements to the first $3 \mathrm{~ms}$ after the response onset (Kudo and Yamada, 1987). We defined the duration of the inhibition as the intersection of the regression line calculated from data with the $x$-axis (GraphPad Prism 5.01 software).

Quantification of polysynaptic responses. We rectified VR signals and measured the areas under the curve from 3 to $100 \mathrm{~ms}$ after response onset (Clampfit 10.2 software). The effect of the drug was considered 30-60 min following bath application.

Quantification of rate-dependent depression. We delivered 15 stimulations at various frequencies ( $20 \mathrm{~s}$ between each series) and we normalized the amplitude of monosynaptic responses (the first three discarded) to the controls evoked at $20 \mathrm{~s}$ intervals (mean of 5 pulses). We took into account at least three series of stimulations before and 30-60 min after the onset of drug application.

Intracellular recordings. After removing the pia, we recorded lumbar $\mathrm{MNs}$ intracellularly using glass microelectrodes filled with $2 \mathrm{M} \mathrm{K}$-acetate (70-100 $\mathrm{M} \Omega$ resistance). We recorded intracellular potentials in the discontinuous current-clamp mode (Axoclamp 2B amplifier; Digidata 1200 interface; pClamp9 software; Molecular Devices). We considered only neurons exhibiting a stable $(>15 \mathrm{~min})$ resting membrane potential $\left(V_{\text {rest }}\right)$ for analysis. We identified MNs in the L4 or L5 segments by their antidromic response to VR stimulation. We used glass suction electrode to stimulate the ipsilateral ventral funiculus at the L2-L3 level. Such stimulations induced $\mathrm{GABA}_{\mathrm{A}}$ - and glycine-mediated IPSPs in the presence of DL-2-amino-5-phosphonovaleric acid (DL-APV; $50 \mu \mathrm{M}$ ) and 6-cyano-7-nitroquinoxaline-2,3-dione (CNQX; $10 \mu \mathrm{M}$; Boulenguez et al., 2010; Bos et al., 2013). We recorded IPSPs at various holding potentials (500-ms-long current pulses) and collected at least 20 values for each MN. We measured and plotted amplitudes of IPSPs against holding potentials and obtained $\mathrm{E}_{\mathrm{IPSP}}$ from the regression line (GraphPad Prism 5.01 software)

Drugs. We purchased CNQX and APV from Abcam, whereas VU0240551, $\mathrm{ZnCl}_{2}$, strychnine, and picrotoxin were from SigmaAldrich. VU0255011 (or ML077) and VU0463271 were generous gifts from Vanderbilt University. VU0240551, VU0255011, and VU0463271 will be referred as "VU compounds" in the following text and figure legends. Strychnine and picrotoxin were prepared in ACSF, whereas VU compounds in DMSO (final concentration of $0.1 \%$ ). We checked that $0.1 \%$ DMSO alone for $2 \mathrm{~h}$ has no effect on monosynaptic reflexes and reciprocal inhibition $(n=2)$. $\mathrm{ZnCl}_{2}$ was prepared in $\mathrm{NaH}_{2} \mathrm{PO}_{4}$-free ACSF to avoid precipitation of the metal (Chorin et al., 2011).

Statistical analysis. All data are reported as mean \pm SE. Statistical comparisons between small samples were performed using nonparametric 
A
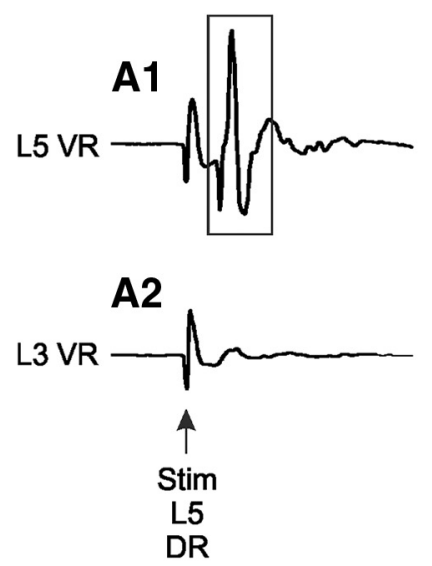

B

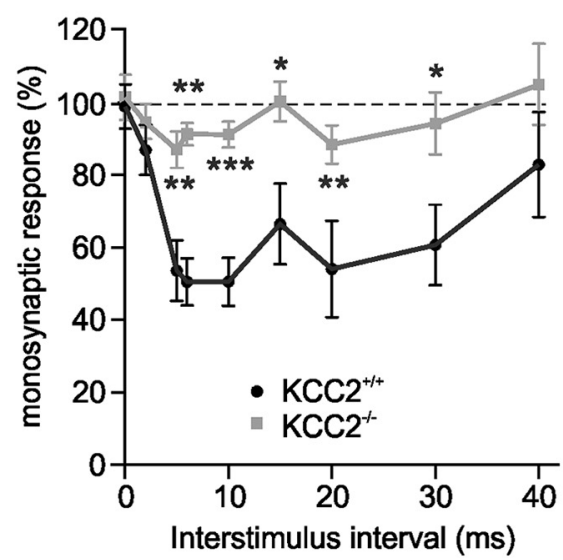

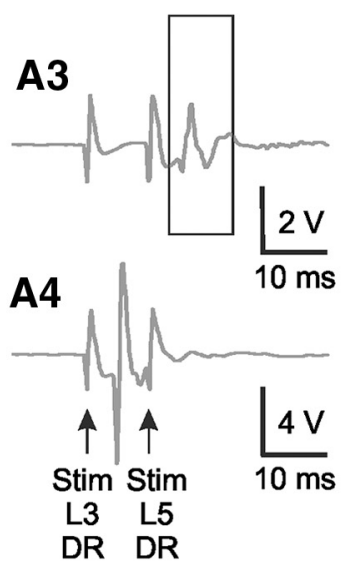

C

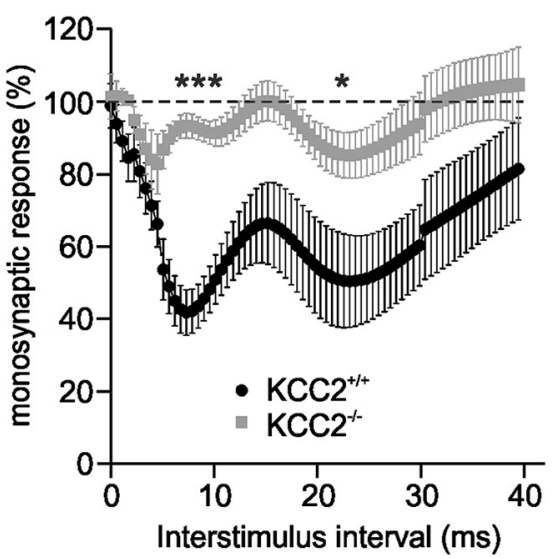

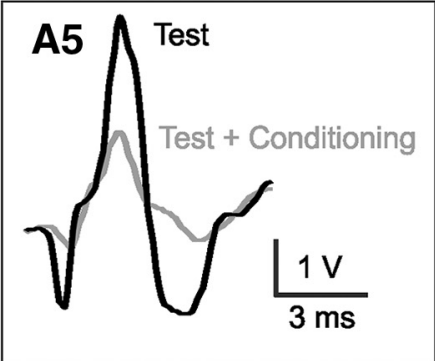

D

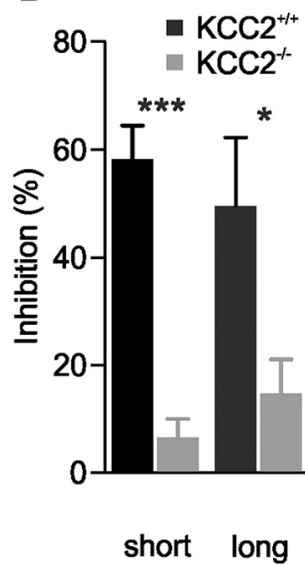

Figure 1. The strength of reciprocal inhibition depends on KCC2 expression in neonatal mice. $\boldsymbol{A}$, Representative traces of extracellular recordings from $L 5$ and $L 3$ VRs ( $\mathbf{A} \mathbf{1}, \boldsymbol{A 3}$ and $\boldsymbol{A 2}, \boldsymbol{A 4}$, respectively) of a P6 KCC2 ${ }^{+/+}$mouse. Black traces show the responses to the L5 DR stimulation (Test) whose intensity is sufficient to evoke a monosynaptic reflex in L5 VR. Gray traces show the responses when the L5 DR stimulation, at the same intensity, was preceded by a conditioning stimulation of the L3 DR (Test + Conditioning) that is sufficient to evoke a monosynaptic reflex in L3 VR (interval of $10 \mathrm{~ms}$ ). $\boldsymbol{A}$, Enlargement of superimposed monosynaptic responses. $\boldsymbol{B}, \boldsymbol{C}$, Amplitude of the test response plotted against the interstimulus interval between conditioning and test stimulations. Average normalized strength of inhibition, represented from raw data $(\boldsymbol{B})$ or after a fitting analysis using spline/lowess, cubic option $(\boldsymbol{C})$ showing two distinct phases of inhibition. Curves were obtained from $5 \mathrm{KCC}^{+/+}$and $10 \mathrm{KCC}^{-/-} \mathrm{P} 4-\mathrm{P} 6$ mice with at least three observations at each delay. Note that the discontinuity after 30 ms interval is due to a different number of observations. $\boldsymbol{D}$, Histograms summarizing the strength of reciprocal inhibition at short (7.3 ms) and long ( $23.1 \mathrm{~ms})$ interstimulus intervals. Statistical differences between $\mathrm{KCC} 2^{+/+}$and $\mathrm{KCC} 2^{-/-}$ mice are noted above each delay in $\boldsymbol{B}$ and above short and long delays in $\boldsymbol{C}$ and $\boldsymbol{D}$ (Mann-Whitney test; ${ }^{*} p<0.05,{ }^{* *} p<0.01,{ }^{* * *} p<0.001$ ).

Wilcoxon or Mann-Whitney tests (for comparing two paired or unpaired groups, respectively; GraphPad Prism 5.01 software). Differences were considered to be significant at ${ }^{\star} p<0.05,{ }^{* *} p<0.01$, and ${ }^{* * *} p<$ 0.001 .

\section{Results}

The strength of reciprocal inhibition depends on the level of KCC2 expression in neonatal mice

We started by examining the strength of reciprocal inhibition in KCC2 (Slc12a5) knock-out mice from postnatal day (P)4 to P6. Homozygous $\mathrm{KCC}^{-1-}$ animals retain $\sim 20 \%$ of the KCC2 amounts expressed in the spinal cord of wild-type $\mathrm{KCC} 2^{+/+}$animals (Woo et al., 2002; Stil et al., 2011). An electrical stimulation of the L5 DR evoked a monosynaptic response in the homonymous ipsilateral VR (Fig. 1A1; KCC $2^{+/+}$mouse, P6) with no or little response in the L3 VR (Fig. 1A2). A conditioning stimulation was then delivered to the ipsilateral L3 DR, generating a monosynaptic response in L3 VR (Fig. 1A4). Such stimulation attenuated the amplitude of the L5 monosynaptic reflex if delivered within an appropriate time window before the L5 DR stimulus (Fig. 1A3,A5). Different delays between the two stimulations (L3 DR before L5 DR) were tested. The L5 response was reduced in amplitude for intervals in the range of $2-40 \mathrm{~ms}$ (Fig. $1 \mathrm{~B}, \mathrm{C}$ ), in agreement with earlier observations in newborn mice (Sonner and Ladle, 2013). We then compared the strength of reciprocal inhibition between wild-type $\mathrm{KCC}^{+/+}$and KCC2-deficient mice. Figure $1 B$ shows the values obtained for each delay from the two genotypes $\left(\mathrm{KCC}^{+/+}, n=5\right.$; $\left.\mathrm{KCC}^{-/-}, n=10\right)$. Significant differences were observed at intervals ranging from 5 to $30 \mathrm{~ms}$ ( $p<0.05, p<0.01, p<0.001$, Mann-Whitney test). To further characterize the time course of the inhibition, we fitted individual traces by means of the spline/lowess, cubic option (see Materials and Methods; Fig. $1 C$ ). This demonstrated that $\mathrm{KCC} 2^{+/+}$mice displayed two phases of inhibition peaking at interstimulus intervals of $7.3 \mathrm{~ms}$ (strength of inhibition: $58.2 \pm 6.3 \%$; Fig. $1 C, D$ ) and $23.1 \mathrm{~ms}$ ( $49.6 \pm 12.7 \%$; Fig. $1 C, D)$, respectively. The two components have different pharmacological profiles, the shortinterval inhibition being consistent with the classical glycinergic disynaptic reciprocal inhibition whereas the long-latency component relies mainly on presynaptic inhibition mediated by GABAergic INs (Sonner and Ladle, 2013). In KCC2 ${ }^{-1-}$ mice, compared with wild-type animals, the strength of inhibition was markedly reduced to $6.5 \pm 3.4 \%$ (88.8\% reduction; Fig. $1 C, D$; $p<0.001$, Mann-Whitney test) and $14.8 \pm 6.3 \%$ (70.2\% reduction; Fig. $1 C, D ; p<0.05$, Mann-Whitney test) at short and long 
A

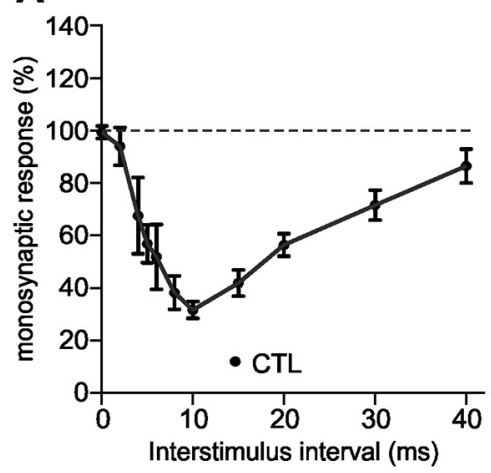

D

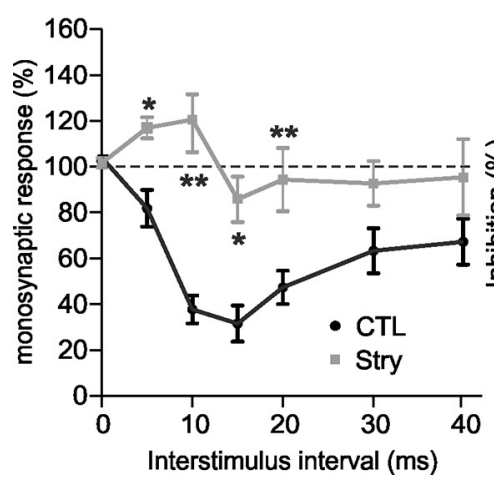

B

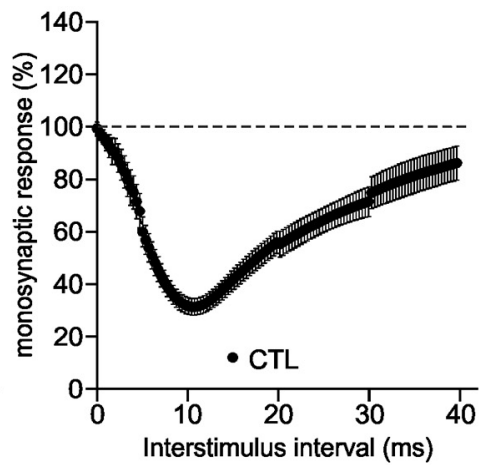

C

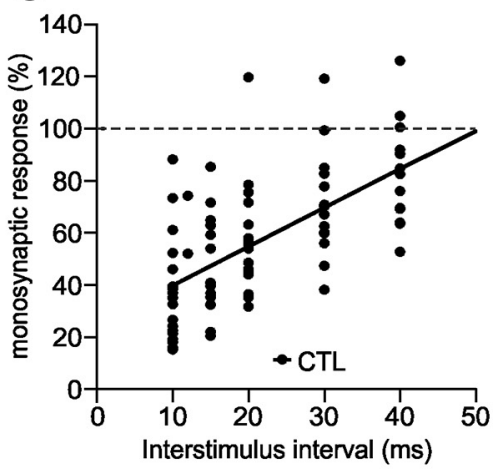

E
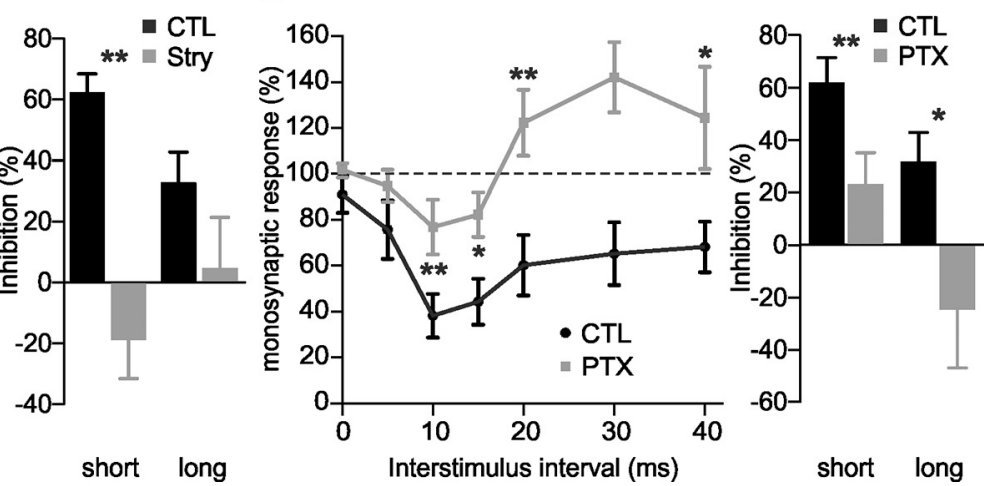

Figure 2. Contribution of GABA and glycine to reciprocal inhibition in neonatal rats. $A, B$, Amplitude of the test response. Average normalized strength of inhibition, represented from raw data $(\boldsymbol{A})$ or after a fitting analysis using spline/lowess, cubic option (B), which shows a single phase of inhibition (peaking at $10.8 \mathrm{~ms}$ ). The curve was obtained from $17 \mathrm{P4}-\mathrm{P} 6 \mathrm{rats}$ with at least three observations at each delay. $C$, Linear regression analysis of the strength of inhibition at delays larger than $10 \mathrm{~ms}(r=0.62)$. The intersection of the regression line with the $x$-axis gives the duration of the inhibition. $\boldsymbol{D}, \boldsymbol{E}$, Amplitude of the test response before (CTL) and $20-45$ min after strychnine (D; Stry, 0.4-1 $\mu \mathrm{m} ; 9$ P4-P6 rats) or picrotoxin (E; PTX, $20 \mu \mathrm{m} ; 8$ P4-P6 rats). At least four observations were made for each delay. Histograms represent the strength of inhibition at short and long interstimulus intervals (10 and $40 \mathrm{~ms}$, respectively) before and after drug application. Statistical differences between CTL and Stry, and between CTL and PTX are noted above delays and histograms in $\boldsymbol{D}$ and $\boldsymbol{E}$ (Wilcoxon test; ${ }^{*} p<0.05,{ }^{* *} p<0.01$ ).

intervals, respectively. An inhibition however persisted at the two intervals in KCC2-deficient mice as response amplitudes in the presence and absence of a conditioning stimulus were significantly different ( $p<0.05$, Wilcoxon test). These results provide the first demonstration in neonatal mice that KCC2 cotransporters are important in regulating the strength of reciprocal inhibition.

\section{Reciprocal inhibition is reduced after neonatal SCI}

The next series of experiments aimed at investigating whether the downregulation of KCC2 that is induced by neonatal SCI in rat (Jean-Xavier et al., 2006; Boulenguez et al., 2010) has any functional impact on reciprocal inhibition. However, to the best of our knowledge, the protocol used by Sonner and Ladle (2013) in mice has never been described in neonatal rats. We therefore performed a reference study on the latter model $(n=17$; Fig. $2 A-C)$. The time course of inhibition was somewhat different from the one observed in mice as the same fit analysis used above (spline/lowess, cubic; see Materials and Methods) revealed a single phase of inhibition reaching $68.7 \pm 3.2 \%$ at $10.8 \mathrm{~ms}$ (Fig. $2 B$ ). The linear regression analysis of the data after the peak of inhibition revealed a duration of inhibition of $50.4 \mathrm{~ms}$ in newborn rats (Fig. 2C). We next used pharmacological compounds to specifically block glycine or $\mathrm{GABA}_{\mathrm{A}}$ receptors. After a control period of at least $1 \mathrm{~h}$, we incubated different spinal cord preparations with strychnine $(0.4-1 \mu \mathrm{M}, n=9)$ or picrotoxin $(20 \mu \mathrm{M}, n=8)$. We compared the values calculated for each delay before and after drug application (Fig. $2 D, E ; p<0.05, p<0.01$, Wilcoxon test). Bath application of strychnine lead to a facilitation at $5-10 \mathrm{~ms}$ (Fig. $2 D ; 19 \pm 12.6 \%$ facilitation vs $62.3 \pm 6.1 \%$ inhibition at 10 ms, $n=9$; $p<0.05$, Wilcoxon test) and the inhibition was abolished at longer intervals $(>15 \mathrm{~ms} ; p>0.05$, Wilcoxon test). Picrotoxin significantly reduced the inhibition at short intervals (10-15 ms; $p<0.05, p<0.01$, Wilcoxon test), such that response amplitudes in the absence and presence of conditioning stimulation were not significantly different $(p>0.05$, Wilcoxon test). A trend toward a facilitation $(p>0.05$, Wilcoxon test) was observed at longer intervals ( $>20 \mathrm{~ms}$; Fig. $2 E ; 24.4 \pm 22.3 \%$ facilitation compared with $31.9 \pm 11 \%$ inhibition at $40 \mathrm{~ms}, n=6$ ). Together, these results indicate that most of the short- (5-20 ms) and long-latency $(>20 \mathrm{~ms}$ ) components of inhibition at the end of the first postnatal week in rats are mediated by glycinergic and GABAergic transmissions, respectively.

To further investigate the involvement of KCC2 in reciprocal inhibition, we incubated spinal cord preparations with VU compounds ( $25 \mu \mathrm{M} ; n=6, n=2$, and $n=1$ for VU0240551, VU0255011, and VU0463271, respectively), described as highly specific KCC2 blockers (Delpire et al., 2009, 2012). The strength of reciprocal inhibition was significantly reduced in the presence of these drugs, compared with control observations made over $1 \mathrm{~h}$ (Fig. $3 A, B ; p<0.05, p<0.01$, Wilcoxon test). Some inhibition however persisted at interstimulus intervals smaller than 25 ms ( $p<0.05$; Wilcoxon test). The calculated mean duration of inhibition was also significantly reduced after KCC2 blockade, 

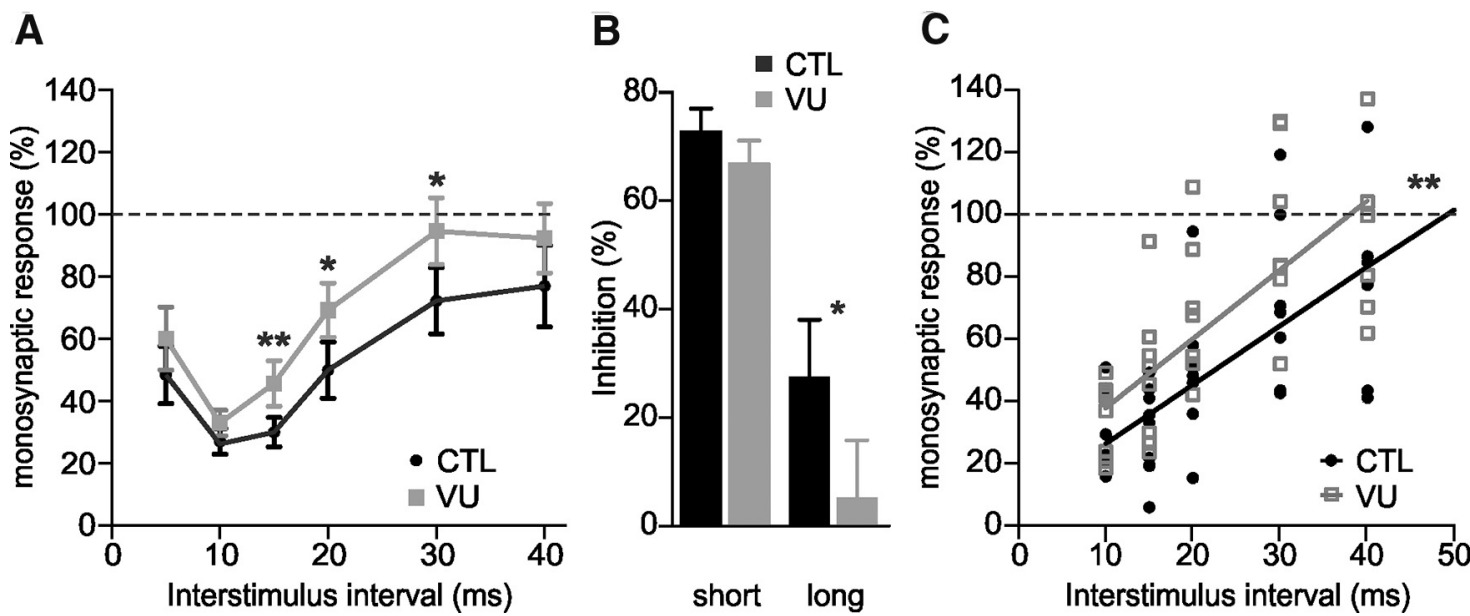

Figure 3. Pharmacological blockade of $\mathrm{KCC} 2$ decreases both the strength and the duration of reciprocal inhibition in neonatal rats. $A$, Amplitude of the test response measured before (CTL) and 30 - $60 \mathrm{~min}$ after application of $25 \mu \mathrm{M} \mathrm{VU}$ compounds. Curves were obtained from nine P4-P6 rats with at least six observations at each delay ( 6 animals received VU0240551, 2 VU0255011, and 1 VU0463271). $\boldsymbol{B}$, Histograms represent the strength of inhibition at short and long interstimulus intervals (10 and $30 \mathrm{~ms}$, respectively) from data reported in $\boldsymbol{A}$. $\boldsymbol{C}$, Linear regression analysis of the data reported in $\boldsymbol{A}(r=0.68$ and $r=0.71$, respectively for CTL and VU conditions). Statistical differences between CTL and VU are noted above delays in $\boldsymbol{A}$, above histograms in $\boldsymbol{B}$ and near regression lines in C (Wilcoxon test and linear regression analysis; ${ }^{*} p<0.05,{ }^{* *} p<0.01$ ).
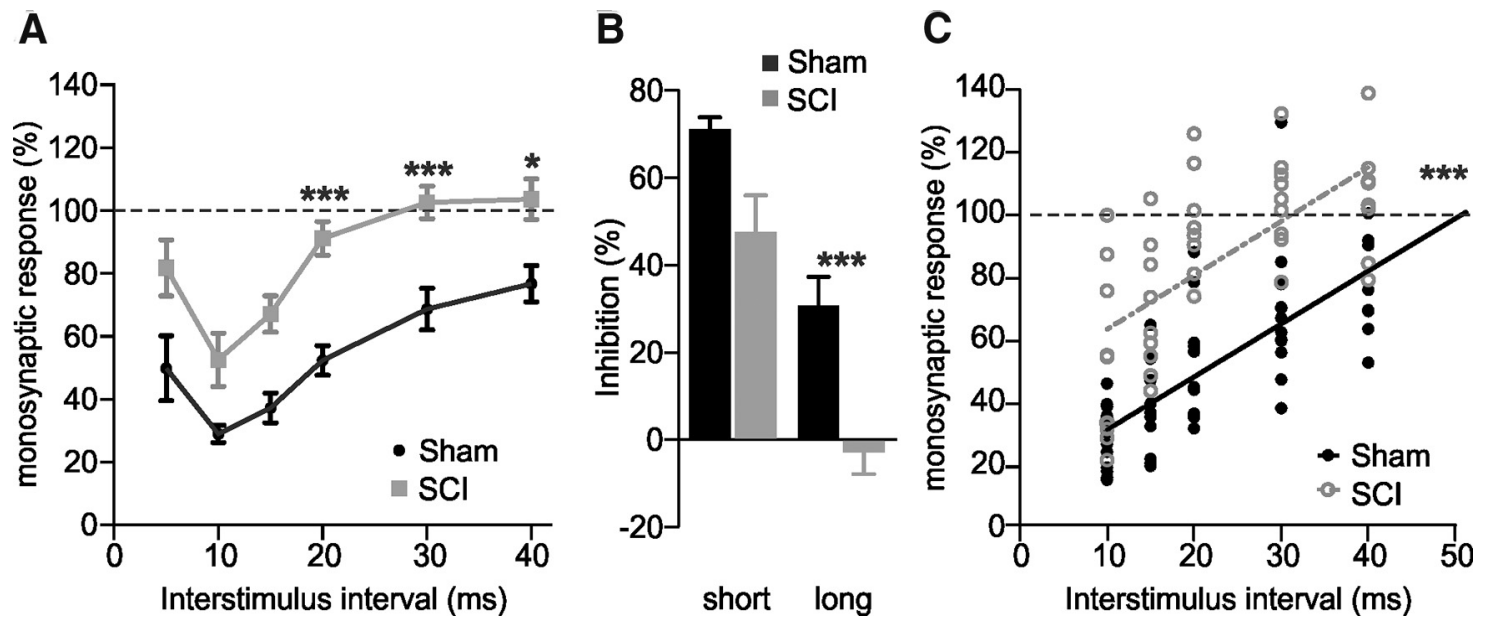

Figure 4. The strength and the duration of reciprocal inhibition are reduced after neonatal SCl in rats. A, Amplitude of the test response in untransected (Sham; 13 animals with at least 7 observations at each delay) and SCI ( 9 animals with at least 8 observations at each delay) P4-P6 rats. B, Histograms represent the strength of inhibition at short and long interstimulus intervals (10 and $30 \mathrm{~ms}$, respectively) from data reported in $\boldsymbol{A}$. C, Linear regression analysis of the data reported in $\boldsymbol{A}(r=0.72$ and $r=0.65$, respectively for Sham and SCl conditions). Statistical differences between Sham and SCl rats are noted above delays in $\boldsymbol{A}$, above histograms in $\boldsymbol{B}$ and near regression lines in $\boldsymbol{C}$ (Mann-Whitney test and linear regression analysis; ${ }^{*} p<0.05,{ }^{* *} p<0.01$, ${ }^{* * *} p<$ 0.001).

from 48.8 to $38 \mathrm{~ms}$ (Fig. $3 C$; $-22.2 \%$; $p<0.01$, linear regression analysis). In support of the results obtained with the genetic model, these data demonstrate that KCC2 function regulates the strength and the duration of reciprocal inhibition in neonatal rodents.

We then explored whether the SCI-induced downregulation of $\mathrm{KCC} 2$ affected the reciprocal inhibition using rats that underwent a complete spinal cord transection at birth (SCI, $n=9$ ), compared with untransected rats (Sham, $n=13$; Fig. 4). There was no statistical difference concerning the amplitude of the L5 monosynaptic response between these two groups at $\mathrm{P} 4-\mathrm{P} 6$ ( $p>$ 0.05 , Mann-Whitney test). The strength of inhibition was reduced for all delays longer than $10 \mathrm{~ms}$ after SCI, compared with sham animals (Fig. 4A, $B$; Mann-Whitney test). The conditioning stimulation had no significant inhibitory effect on the test response at intervals longer than $15 \mathrm{~ms}$ in SCI animals $(p>0.05$, Wilcoxon test). Accordingly, the calculated duration of inhibi- tion was lower in transected rats with a $38.4 \%$ reduction from 50.6 in Sham to $31.2 \mathrm{~ms}$ in SCI rats (Fig. $4 C$; $p<0.001$, linear regression analysis).

\section{Zinc upregulates KCC2 function in MNs and strengthens} reciprocal inhibition after neonatal SCI

We next sought to test the effect of upregulating KCC2 function on reciprocal inhibition. We used zinc that has been shown to upregulate KCC2 activity (Chorin et al., 2011). The effect of zinc chloride on $\mathrm{E}_{\text {IPSP }}$ in lumbar MNs in intact P4-P6 rats was examined at two concentrations ( $1 \mu \mathrm{M}$, gray lines, $n=7$ and $10 \mu \mathrm{M}$, black lines, $n=10$; Fig. $5 A$ ). $\mathrm{ZnCl}_{2}$ hyperpolarized $\mathrm{E}_{\mathrm{IPSP}}$ within 15-20 min and measurements were done 30-60 min after application onset. $\mathrm{E}_{\mathrm{IPSP}}$ was significantly more hyperpolarized when MNs were recorded in the presence of $\mathrm{ZnCl}_{2}$ compared with control conditions $(-4.7 \mathrm{mV}, n=17$; Fig. $5 A$; $p<0.001$, Wilcoxon test; note that differences were also significant when con- 

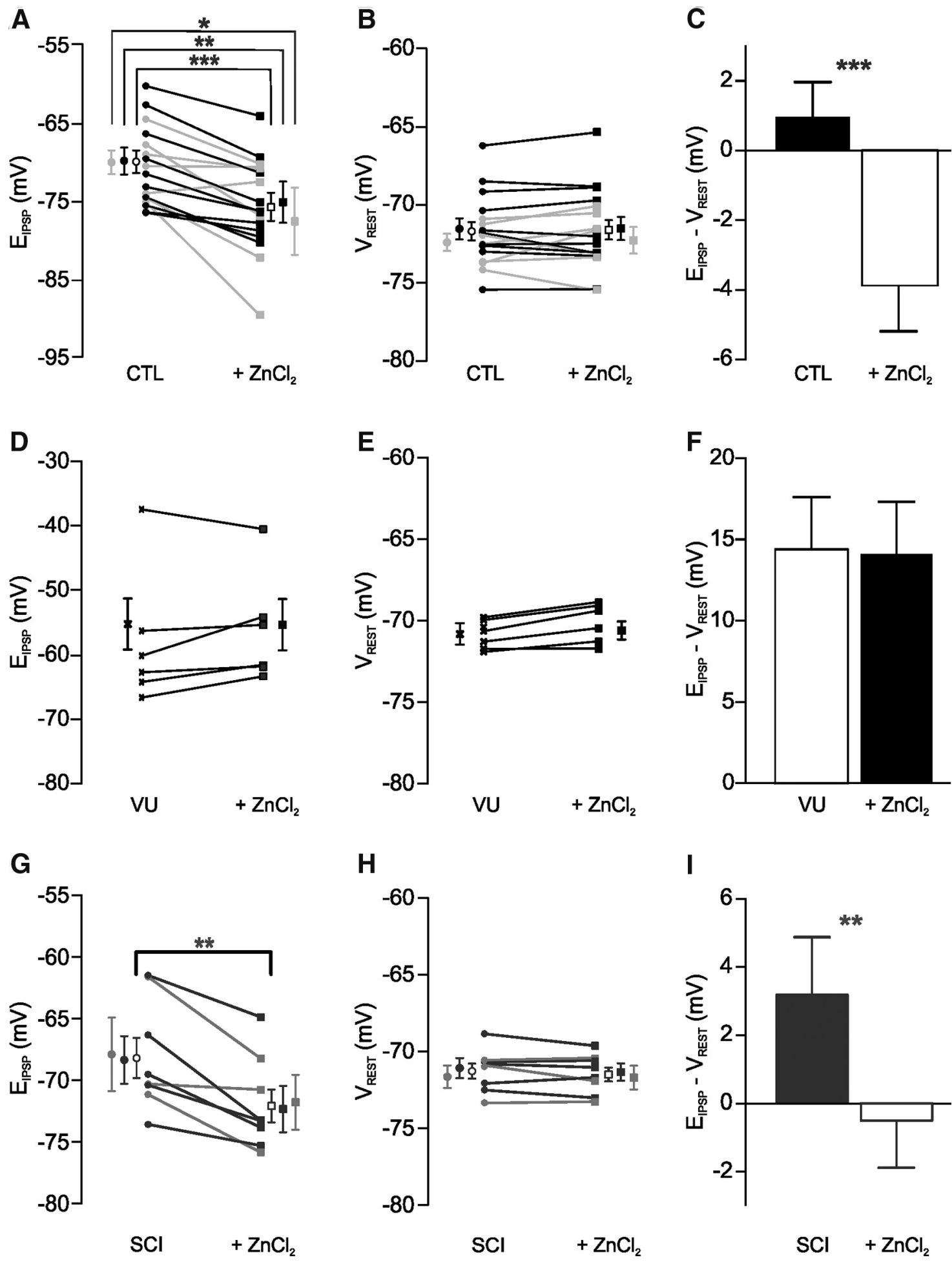

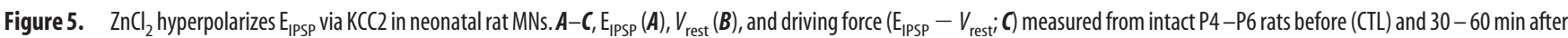
$\mathrm{ZnCl}_{2}(1 \mu \mathrm{M}$, gray, $n=7 ; 10 \mu \mathrm{M}$, black, $n=10)$. Empty symbols indicate mean $\pm \mathrm{SEM}$ of the pooled data. Note that differences are also significant considering each concentration separately: ${ }^{*} 1$ $\mu \mathrm{m}$ and ${ }^{* *} 10 \mu \mathrm{MZnCl}$. D $-\boldsymbol{F}$, Pharmacological blockade of KCC2 by VU compounds prevents the hyperpolarizing shift of $\mathrm{E}_{\mathrm{IPSP}}$ induced by $Z n \mathrm{Cl}_{2}$ application in intact $\mathrm{P} 4-\mathrm{P} 6$ rats. $\mathrm{E}_{\mathrm{PPSP}}(\boldsymbol{D}), V_{\text {rest }}(\boldsymbol{E})$, and driving force $\left(\mathrm{E}_{\mathrm{PSPP}}-V_{\text {resti }} ; \boldsymbol{F}\right)$ measured $10-30 \mathrm{~min}$ after the application of KCC2 blockers $(25 \mu \mathrm{M} \mathrm{VU} ; n=5 \mathrm{VU} 0240551$ and $n=1 \mathrm{VU} 0463271)$ and $30-60 \mathrm{~min}$ after $10 \mu \mathrm{M} \mathrm{ZnCl} 2(n=6)$. $\mathbf{G}-\boldsymbol{I}$, $\mathrm{E}_{\text {IPSP }}(\boldsymbol{G}), V_{\text {rest }}(\boldsymbol{H})$, and driving force $\left(\mathrm{E}_{\text {IPSP }}-V_{\text {rest }} \boldsymbol{I}\right)$ measured from P4-P6 rats that underwent SCl at birth before $(\mathrm{SCl})$ and $30-60$ min after $Z n \mathrm{Cl}_{2}(1 \mu \mathrm{m}, g$ ray, $n=3 ; 10 \mu \mathrm{m}, \mathrm{black}, n=5)$. Empty symbols indicate mean \pm SEM of the pooled data. Statistical differences are noted below values in $\boldsymbol{A}$ and $\mathbf{G}$, and below histograms in $\mathbf{C}$ and $\boldsymbol{I}$ (Wilcoxon test; ${ }^{*} p<0.05,{ }^{* * *} p<0.01,{ }^{* * *} p<0.001$ ).

sidering each concentration separately, $p<0.05$ and $p<0.01$, Wilcoxon test applied for 1 and $10 \mu \mathrm{MnCl}_{2}$, respectively). $\mathrm{ZnCl}_{2}$ had no significant impact on the resting membrane potential ( $V_{\text {rest }}, n=17$; Fig. $5 B ; p>0.05$, Wilcoxon test). Therefore, the driving force increased significantly $(-4.8 \mathrm{mV}, n=17$; Fig. $5 C$; $p<0.001$, Wilcoxon test). As a result, $\mathrm{E}_{\text {IPSP }}$ shifted from above to below $V_{\text {rest }}$. We blocked KCC2 function by VU compounds ( $n=$ 6 in total: $n=5$ for VU0240551 and $n=1$ for VU0463271) which 
A

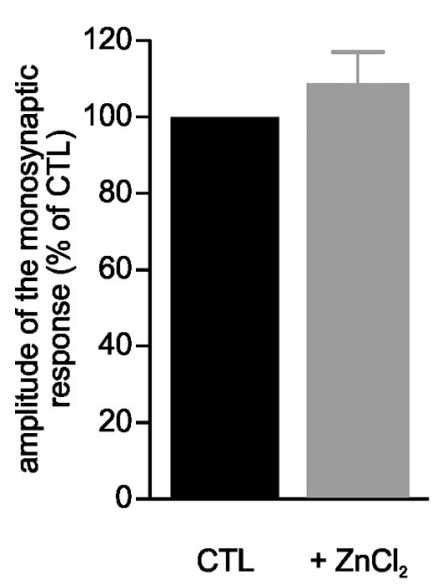

B

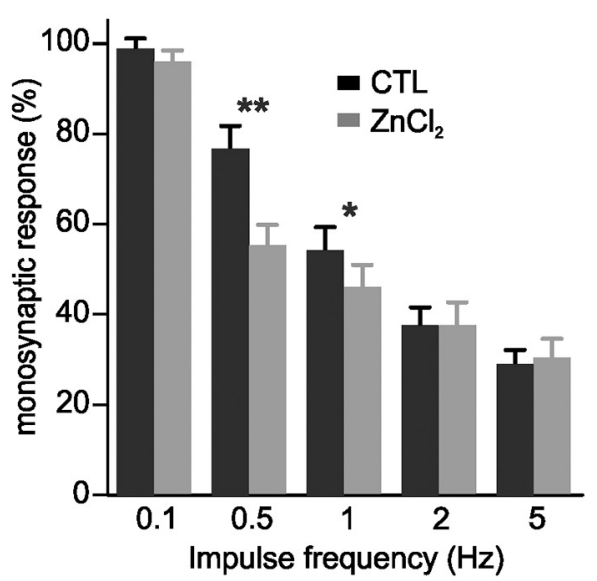

C

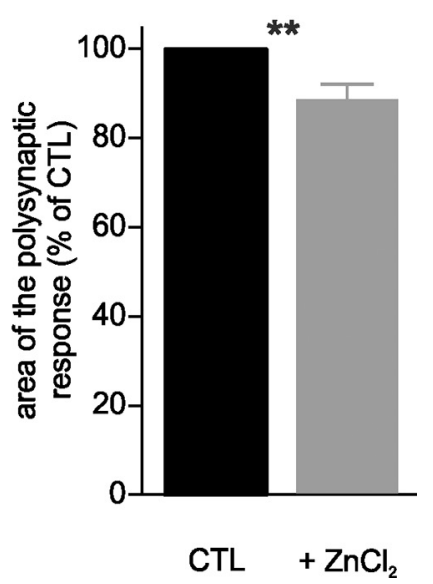

Figure 6. Effects of $\mathrm{ZnCl}_{2}$ on VR responses to homonymous DR stimulation in the $\mathrm{P} 4$ - $\mathrm{P} 6$ rat spinal cord in vitro. $\boldsymbol{A}$, Relative amplitudes of the monosynaptic responses before (CTL) and 30 - 60 min after $\mathrm{ZnCl}_{2}$ ( 1 and $10 \mu \mathrm{M}, n=6$ and $n=11$, respectively; $p>0.05$ ). B, Relative amplitudes of the monosynaptic reflex at different stimulation frequencies before (CTL) and $30-60$ min after $\mathrm{ZnCl}_{2}$ ( 1 and $10 \mu \mathrm{m}, n=6$ and $n=11$, respectively). Twelve values (the first three discarded) were averaged for each animal. The RDD was significantly increased by $\mathrm{ZnCl}$ at 0.5 and $1 \mathrm{~Hz}$. $\mathbf{C}$, Mean areas of the polysynaptic responses before (CTL) and 30-60 min after $1(n=5)$ and $10 \mu \mathrm{m}(n=10) \mathrm{ZnCl}_{2}$. Statistical differences between $\mathrm{CTL}_{\text {and }} \mathrm{ZnCl} \mathrm{Cl}_{2}$ are noted above impulse frequencies in $\boldsymbol{B}$ and above histograms in $\mathrm{C}$ (Wilcoxon test; ${ }^{*} p<0.05,{ }^{* *} p<0.01$ ).

depolarize $\mathrm{E}_{\text {IPSP }}$ (Fig. 5 compare $A, D$ and $C, F ; p<0.01$, MannWhitney test) without any effect on $V_{\text {rest }}(n=6$; Fig. $5 E ; p>0.05$, Wilcoxon test) confirming previous observations (Bos et al., 2013). Importantly, $\mathrm{VU}$ compounds prevented the $\mathrm{ZnCl}_{2}$ induced hyperpolarizing shift of $\mathrm{E}_{\text {IPSPs }}(n=6$; Fig. $5 D, F ; p>$ 0.05 , Wilcoxon test), suggesting that $\mathrm{ZnCl}_{2}$ modulates chloride homeostasis through an upregulation of KCC2 function.

We also tested $\mathrm{ZnCl}_{2}$ on $\mathrm{MNs}$ recorded from animals that underwent a SCI at birth $(1 \mu \mathrm{M}, n=3$, gray lines and $10 \mu \mathrm{M}$ $\mathrm{ZnCl}_{2}, n=5$, black lines; Fig. $\left.5 G-I\right)$. $\mathrm{E}_{\mathrm{IPSP}}$ was significantly more hyperpolarized when MNs were recorded in the presence of $\mathrm{ZnCl}_{2}$ compared with control conditions $(-3.9 \mathrm{mV}, n=8$; Fig. $5 G ; p<0.01$, Wilcoxon test). $\mathrm{ZnCl}_{2}$ had no significant impact on $V_{\text {rest }}(n=8$; Fig. $5 H ; p>0.05$, Wilcoxon test). Therefore, the driving force increased significantly 30-60 min after the onset of $\mathrm{ZnCl}_{2}$ application $(-3.7 \mathrm{mV}, n=8$; Fig. $5 C$; $p<0.01$, Wilcoxon test), and $\mathrm{E}_{\mathrm{IPSP}}$ shifted from above to below $V_{\text {rest }}$.

The amplitude of the monosynaptic response evoked in a VR by supramaximal stimulation of the homonymous ipsilateral DR in vitro decreases when the stimulation occurs repeatedly, and this reduction becomes more important as the frequency of stimulation increases [rate-dependent depression (RDD); Bos et al., 2013]. As the RDD is reduced when KCC2 function is genetically or pharmacologically reduced (Boulenguez et al., 2010; Bos et al., 2013), we hypothesized that hyperpolarizing $\mathrm{E}_{\text {IPSP }}$ by $\mathrm{ZnCl}_{2}$ would increase the RDD. The amplitude of the monosynaptic response was not affected by $\mathrm{ZnCl}_{2}$ ( 1 and $10 \mu \mathrm{M}, n=17$; Fig. $6 A$; $p>0.05$, Wilcoxon test). $\mathrm{ZnCl}_{2}$ significantly reduced the amplitude of the monosynaptic response elicited by repetitive stimulation at 0.5 and $1 \mathrm{~Hz}(n=17$; Fig. $6 B$; $p<0.05$ and $p<0.01$, Wilcoxon test). Linear regressions obtained from CTL and $\mathrm{ZnCl}_{2}$ conditions were significantly different $(p<0.05$, regression line analysis). Regarding the polysynaptic response, we noticed a significant reduction $(-11.1 \%)$ after $\mathrm{ZnCl}_{2}$ compared with control ( $n=16$; Fig. $6 C ; p<0.01$, Wilcoxon test).

Finally, we investigated whether $\mathrm{ZnCl}_{2}$ application was able to increase reciprocal inhibition in rats in control and pathological conditions (Fig. 7). The strength of reciprocal inhibition recorded from intact rats was quite similar before and after $10 \mu \mathrm{M}$
$\mathrm{ZnCl}_{2}$, comparing each delay $(n=8$; Fig. $7 A, B ; p>0.05$, Wilcoxon test). Similarly, we did not observe any significant difference regarding the duration of reciprocal inhibition $(56.9 \mathrm{~ms}$ and $50.2 \mathrm{~ms}$ before and after $\mathrm{ZnCl}_{2}, n=8$; Fig. $7 C ; p>0.05$, Wilcoxon test). By contrast, $\mathrm{ZnCl}_{2}$ had an effect after neonatal spinal cord transection as it markedly increased reciprocal inhibition. Indeed, the strength $(10-20 \mathrm{~ms}, n=7$; Fig. $7 D, E ; p<0.05$, Wilcoxon test) and duration (22\% gain switching from 31.2 to 38.1 ms, $n=7$; Fig. $7 F$; $p<0.01$, regression line analysis) of the inhibition were both significantly increased after $10 \mu \mathrm{M} \mathrm{ZnCl}_{2}$.

\section{Discussion}

This study demonstrates that reducing the expression (genetic model) or the functionality (pharmacological blockade) of KCC2 reduces the strength of a well characterized inhibition in the spinal cord. Reciprocally, in pathological conditions such as after SCI, boosting KCC2 function by zinc ions enabled to restore endogenous inhibition.

\section{Reciprocal inhibition in vitro in neonatal rodents}

The pathway mediating reciprocal inhibition from muscle spindle afferents (Ia axons) to MNs supplying antagonistic muscles has been well studied in adult cats (Hultborn and Udo, 1972), but little was known until recently about how this disynaptic pathway develops (Wang et al., 2008; Sonner and Ladle, 2013). Using extracellular physiological techniques from hemisected spinal cord preparations isolated from 1-week-old mice, the latter authors described two distinct phases of inhibition at 6.5 and $23 \mathrm{~ms}$ with a maximum degree of inhibition of 71 and $52 \%$, respectively. The time course of the inhibition obtained in our study is in accordance with these earlier data (7.3 and $23.1 \mathrm{~ms}$ with degrees of inhibition of 58 and $50 \%$, respectively). The experiments performed by Sonner and Laddle (2013) further revealed that the two inhibitory phases were supported by separate pathways that did not mature at the same time. A disynaptic reciprocal glycinergic pathway is responsible for the early phase of inhibition and is functional at birth whereas the longer latency inhibition relies on presynaptic GABAergic inhibition of Ia afferents, that is only weakly observed at $\mathrm{P} 0$. 
A

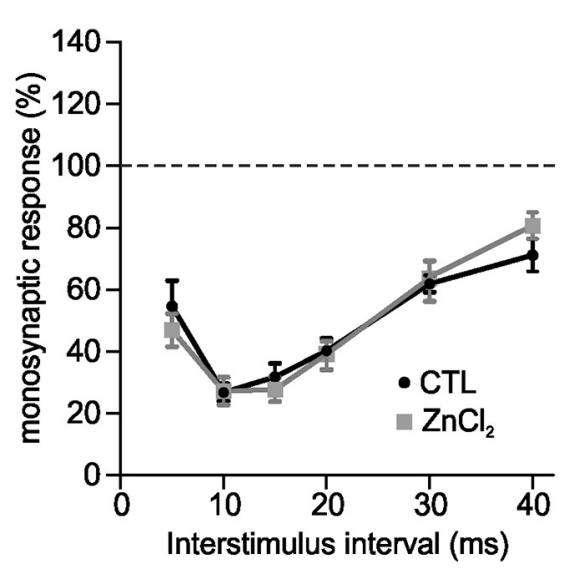

D

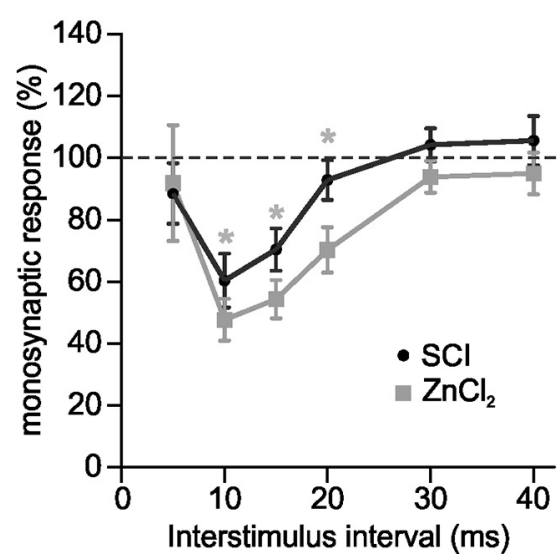

B

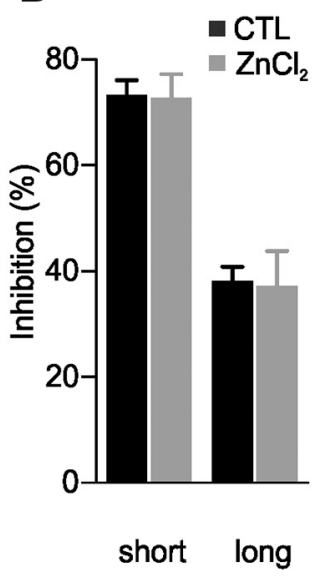

E

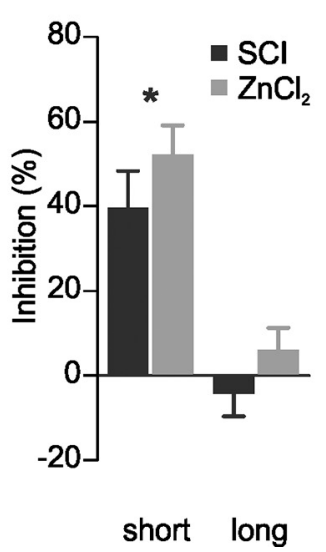

C

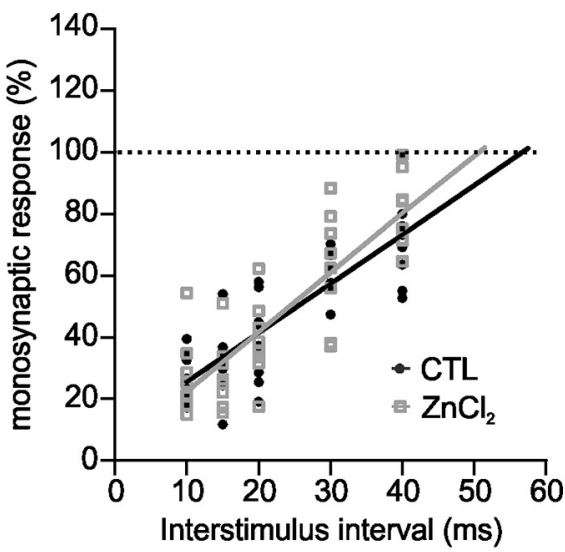

$\mathbf{F}$

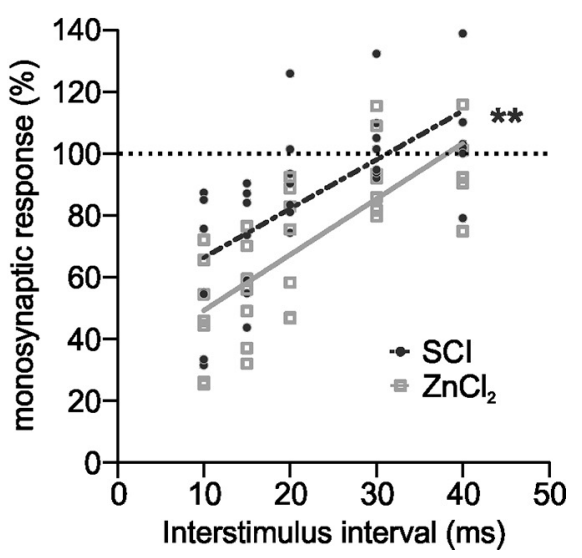

Figure 7. $\mathrm{ZnCl}_{2}$ increases both the strength and the duration of reciprocal inhibition only in $\mathrm{SCl}$ neonatal rats. $A$, Amplitude of the normalized test response before (CTL) and $30-60 \mathrm{~min}$ after $\mathrm{ZnCl} \mathrm{C}_{2}$ $(10 \mu \mathrm{m})$ in untransected P4-P6 rats. Curves were obtained from eight animals with eight observations at each delay. $\boldsymbol{B}$, Histograms represent the strength of inhibition at short and long interstimulus intervals ( 10 and $30 \mathrm{~ms}$, respectively). C, Linear regression analysis of the data reported in $\boldsymbol{A}\left(r=0.83\right.$ and $r=0.84$, respectively for $\mathrm{CTL}_{\text {and } Z \mathrm{ZCl}}$ conditions). $\boldsymbol{D}$, Amplitude of the test response before and $30-60 \mathrm{~min}$ after $\mathrm{ZnCl}_{2}(10 \mu \mathrm{m})$ in SCI P4-P6 rats. Curves were obtained from seven animals with at least five observations at each delay. $E$, Histograms represent the strength of inhibition at short and long interstimulus intervals (10 and $30 \mathrm{~ms}$, respectively). $\boldsymbol{F}$, Linear regression analysis of the data reported in $\boldsymbol{D}(r=0.67$ and $r=0.75$, respectively for $\mathrm{SCl}$ and $\mathrm{ZnCl}$ conditions). Statistical differences between $\mathrm{SCl}$ and $\mathrm{ZnCl}_{2}$ conditions are noted above delays in $\boldsymbol{D}$, above histograms in $\boldsymbol{E}$ and near regression lines in $\boldsymbol{F}$ (Wilcoxon test and linear regression analysis; $\left.{ }^{*} p<0.05,{ }^{* *} p<0.01\right)$.

The time course obtained with rats in the present study was quite different from that in mice of the same age. A single phase was indeed observed at $\sim 11 \mathrm{~ms}$. At first sight, this may suggest that, similar to mice, presynaptic inhibition might be immature during the first postnatal week. This, however, appears unlikely as blocking $\mathrm{GABA}_{\mathrm{A}}$-receptors had a marked effect on the late part of the inhibition. It is noteworthy that the effect of pharmacological blockade of glycine and $\mathrm{GABA}_{\mathrm{A}}$ receptors in rats was not as clearcut as in mice, in which strychnine and bicuculline affect mainly the early and the late inhibitory phases, respectively. In rats, the two antagonists affected the inhibition throughout its time course, suggesting a corelease of glycine and GABA by the interneurons involved in the disynaptic reciprocal, short-interval, inhibition and a strong contribution of glycine to a polysynaptic postsynaptic inhibition at long delays, that would be superimposed on presynaptic inhibition.

The level of KCC2 function sets the strength of postsynaptic inhibition

The $k c c 2$ gene codes for two isoforms, KCC2a and KCC2b, which differ in their N-termini (Uvarov et al., 2007, 2009). KCC2a contributes $20-50 \%$ and $5-10 \%$ of total KCC 2 mRNA expression in the neonatal and mature mouse brain, respectively, indicating that the expression of the KCC2b isoform markedly increases during development, whereas that of KCC2a remains relatively constant (Uvarov et al., 2007). Mice that lack both KCC2 isoforms die at birth due to severe motor defects, including disrupted respiratory rhythm (Hübner et al., 2001), whereas the mice we used in the present study, with a targeted disruption of the first exon of KCC2b, survived for up to 2 weeks (Woo et al., 2002).

In the present study, the inhibition of the L5 monosynaptic reflex, induced by stimulating the L3 dorsal root, was shown to be significantly reduced in KCC2b KO mice or after blocking KCC2 in neonatal rats. Both the early and late phases of inhibition were affected which is in agreement with a contribution of postsynaptic inhibition to these two phases. Both the genetic and the pharmacological downregulation of KCC2 expression/function lead to a $10-20 \mathrm{mV}$ depolarizing shift of chloride equilibrium potential $\left(E_{\mathrm{Cl}}\right)$ in lumbar MNs (Hübner et al., 2001; Jean-Xavier et al., 2006; Boulenguez et al., 2010; Bos et al., 2013). Depolarizing $\operatorname{IPSPs}\left(E_{\mathrm{Cl}}>V_{\text {Rest }}\right)$ are less able to suppress suprathreshold excitatory events than hyperpolarizing IPSPs, suggesting that the depolarization counteracts and can overcome the shunting effect 
(Jean-Xavier et al., 2007). Similarly, the duration of inhibition and $E_{\mathrm{Cl}}$ are negatively correlated, in agreement with the present observations that the duration of inhibition is decreased after reducing KCC2 function/expression. A major conclusion of the simulations we made was that membrane potential changes spread electrotonically as inhibitory synapses are moved away from the soma, whereas the shunting is local (Jean-Xavier et al., 2007). As a consequence, depolarizing IPSPs facilitate action potential generation by subthreshold excitatory events in the late phase of the response. The window of facilitation becomes wider as $E_{\mathrm{Cl}}$ becomes more depolarized and starts earlier as inhibitory synapses are moved away from the excitatory input. Interestingly, for distal inhibitory inputs, the effect on excitations generated at the soma level, can switch from inhibition (of suprathreshold EPSPs) to facilitation (of subthreshold EPSPs) within a narrow window of $E_{\mathrm{Cl}}$ values, close to the resting membrane potential. In summary, this study demonstrated that small depolarizing IPSPs can either inhibit or facilitate excitatory inputs, depending on timing and location (van den Pol et al., 1996; Gao et al., 1998; Gulledge and Stuart, 2003; Prescott et al., 2006; Jean-Xavier et al., 2007; Ostroumov et al., 2011). In addition to an effect on the integration of excitations, any alteration of KCC2 function may influence tonically active glycinergic/GABAergic currents in the postsynaptic neuron and thereby change its excitability.

The stronger disinhibition observed after KCC2 knock-down $\left(\mathrm{KCC} 2{ }^{-1-}\right.$ mice; Fig. $1 B$ ) compared with KCC2 blockade (rats; Fig. $3 A$ ) is at first sight surprising. However, at the concentrations of VU compounds used, the blockade of KCC2 is likely partial as suggested by an $\mathrm{E}_{\mathrm{IPSP}}$ of $\sim-60 \mathrm{mV}$ (Bos et al., 2013; the present study). By contrast, the $80 \%$ reduction in KCC2 expression in transgenic mice leads to an $\mathrm{E}_{\text {IPSP }}$ of $\sim-49 \mathrm{mV}$ (Stil et al., 2011). The above-mentioned modeling studies showed that such a $\sim 10$ $\mathrm{mV}$ difference in the shift of $\mathrm{E}_{\mathrm{IPSP}}$ has dramatic effects on the strength of postsynaptic inhibition.

\section{Zinc restores endogenous inhibition in pathological conditions}

Ipsilateral cocontraction of flexors and extensors is commonly observed in SCI patients (Harkema, 2008). The strength of several well characterized inhibitory mechanisms, such as presynaptic (Katz, 1999), recurrent (Mazzocchio and Rossi, 1997), and reciprocal (Boorman et al., 1996) inhibitions is reduced after SCI. A reciprocal facilitation instead of reciprocal inhibition may even appear (Crone et al., 2003). A reduction in the expression of KCC2 in the plasma membrane of MNs was suggested to be responsible for the reduced inhibition after SCI in adult (Boulenguez et al., 2010) and neonatal (Jean-Xavier et al., 2006; Bos et al., 2013) rats. Therefore, boosting the activity and/or the expression of KCC2 transporters by a pharmacological tool should restore endogenous inhibition.

Extracellular $\mathrm{ZnCl}_{2}$ was recently described as an enhancer of KCC2 activity and surface expression, thereby inducing a hyperpolarizing shift in $\mathrm{GABA}_{\mathrm{A}}$ reversal potential in rat hippocampal and cortical neurons (Chorin et al., 2011; Saadi et al., 2012). Several studies showed the presence of zinc-enriched neurons in the motor neuron area of rodent spinal cords suggesting a role of their boutons in the regulation of motor functions (Schrøder et al., 2000; Wang et al., 2001). Here, we demonstrate in vitro that $\mathrm{ZnCl}_{2}$ hyperpolarizes $\mathrm{E}_{\mathrm{IPSP}}$ in lumbar MNs in both control and SCI rats. This effect was prevented by the application of highly specific KCC2 blockers (Delpire et al., 2009, 2012), which is consistent with the requirement of KCC2 for the zinc-induced $\mathrm{E}_{\mathrm{IPSP}}$ shift.
Because the RDD of the monosynaptic response is markedly reduced when KCC2 is blocked or downregulated in pathological conditions (Boulenguez et al., 2010; Bos et al., 2013), we hypothesized that boosting KCC2 function and or expression by $\mathrm{ZnCl}_{2}$ would affect the RDD. As expected, $\mathrm{ZnCl}_{2}$ increased the RDD in vitro neonatal rats. We next considered the polysynaptic response, which results from a mixture of excitation and inhibition in MNs (Wallis and Wu, 1992; Jiang et al., 1999), and we showed a significant decrease by $\mathrm{ZnCl}_{2}$. Altogether, these results prove that $\mathrm{ZnCl}_{2}$ increases the inhibitory tone in the rat spinal cord. Interestingly, regarding reciprocal inhibition, $\mathrm{ZnCl}_{2}$ had no effect on intact rats but partially restored its strength and duration in SCI rats. Simulations showed that increasing KCC2 activity above normal levels has very little effects on $E_{\mathrm{Cl}}$ (Prescott et al., 2006; Doyon et al., 2011), and likely on the strength of postsynaptic inhibition. By contrast, in pathological condition associated with a KCC2 deficiency, $\mathrm{ZnCl}_{2}$ was able to increase reciprocal inhibition.

To conclude, the present study demonstrates that KCC2 appears as an attractive target to restore endogenous inhibition after SCI. Zinc ions may be an effective tool to reach such a goal. The positive effects of zinc supplementation on recovery in pathological conditions have been repeatedly demonstrated. For instance, zinc supplementation improves behavioral and cognitive recovery following traumatic brain injury (Cope et al., 2012). Similarly, zinc supplement reduces neurological damage and promotes the recovery of spinal cord function after acute SCI. An interesting potential mechanism involves a positive effect on BDNF synthesis and release (Wang et al., 2011), as BDNF has been shown to increase KCC2 expression after SCI (Boulenguez et al., 2010).

\section{References}

Boorman GI, Lee RG, Becker WJ, Windhorst UR (1996) Impaired "natural reciprocal inhibition" in patients with spasticity due to incomplete spinal cord injury. Electroencephalogr Clin Neurophysiol 101:84-92. CrossRef Medline

Bos R, Sadlaoud K, Boulenguez P, Buttigieg D, Liabeuf S, Brocard C, Haase G, Bras H, Vinay L (2013) Activation of 5-HT2A receptors upregulates the function of the neuronal K-Cl cotransporter KCC2. Proc Natl Acad Sci U S A 110:348-353. CrossRef Medline

Boulenguez P, Vinay L (2009) Strategies to restore motor functions after spinal cord injury. Curr Opin Neurobiol 19:587-600. CrossRef Medline

Boulenguez P, Liabeuf S, Bos R, Bras H, Jean-Xavier C, Brocard C, Stil A, Darbon P, Cattaert D, Delpire E, Marsala M, Vinay L (2010) Downregulation of the potassium-chloride cotransporter KCC2 contributes to spasticity after spinal cord injury. Nat Med 16:302-307. CrossRef Medline

Chen G, Trombley PQ, van den Pol AN (1996) Excitatory actions of GABA in developing rat hypothalamic neurones. J Physiol 494:451-464. CrossRef Medline

Chorin E, Vinograd O, Fleidervish I, Gilad D, Herrmann S, Sekler I, Aizenman E, Hershfinkel M (2011) Upregulation of KCC2 activity by zincmediated neurotransmission via the mZnR/GPR39 receptor. J Neurosci 31:12916-12926. CrossRef Medline

Cope EC, Morris DR, Scrimgeour AG, Levenson CW (2012) Use of zinc as a treatment for traumatic brain injury in the rat: effects on cognitive and behavioral outcomes. Neurorehabil Neural Repair 26:907-913. CrossRef Medline

Crone C, Johnsen LL, Nielsen J (2000) Reciprocal inhibition in hemiplegic patients: a longitudinal study. Suppl Clin Neurophysiol 53:187-191. CrossRef Medline

Crone C, Johnsen LL, Biering-Sørensen F, Nielsen JB (2003) Appearance of reciprocal facilitation of ankle extensors from ankle flexors in patients with stroke or spinal cord injury. Brain 126:495-507. CrossRef Medline

Curtis DR, Hösli L, Johnston GA, Johnston IH (1968) The hyperpolarization of spinal motoneurones by glycine and related amino acids. Exp Brain Res 5:235-258. Medline

Delpire E, Days E, Lewis LM, Mi D, Kim K, Lindsley CW, Weaver CD (2009) 
Small-molecule screen identifies inhibitors of the neuronal K-Cl cotransporter KCC2. Proc Natl Acad Sci U S A 106:5383-5388. CrossRef Medline

Delpire E, Baranczak A, Waterson AG, Kim K, Kett N, Morrison RD, Daniels JS, Weaver CD, Lindsley CW (2012) Further optimization of the K-Cl cotransporter KCC2 antagonist ML077: development of a highly selective and more potent in vitro probe. Bioorg Med Chem Lett 22:4532-4535. CrossRef Medline

Doyon N, Prescott SA, Castonguay A, Godin AG, Kröger H, De Koninck Y (2011) Efficacy of synaptic inhibition depends on multiple, dynamically interacting mechanisms implicated in chloride homeostasis. PLoS Comput Biol 7:e1002149. CrossRef Medline

Gao XB, van den Pol AN (2001) GABA, not glutamate, a primary transmitter driving action potentials in developing hypothalamic neurons. J Neurophysiol 85:425-434. Medline

Gao XB, Chen G, van den Pol AN (1998) GABA-dependent firing of glutamate-evoked action potentials at AMPA/kainate receptors in developing hypothalamic neurons. J Neurophysiol 79:716-726. Medline

Gulledge AT, Stuart GJ (2003) Excitatory actions of GABA in the cortex. Neuron 37:299-309. CrossRef Medline

Harkema SJ (2008) Plasticity of interneuronal networks of the functionally isolated human spinal cord. Brain Res Rev 57:255-264. CrossRef Medline

Hübner CA, Stein V, Hermans-Borgmeyer I, Meyer T, Ballanyi K, Jentsch TJ (2001) Disruption of KCC2 reveals an essential role of K-Cl cotransport already in early synaptic inhibition. Neuron 30:515-524. CrossRef Medline

Hultborn H, Udo M (1972) Convergence of large muscle spindle (Ia) afferents at interneuronal level in the reciprocal Ia inhibitory pathway to motoneurones. Acta Physiol Scand 84:493-499. CrossRef Medline

Jankowska E (1992) Interneuronal relay in spinal pathways from proprioceptors. Prog Neurobiol 38:335-378. CrossRef Medline

Jankowska E, Lindström S (1972) Morphology of interneurones mediating Ia reciprocal inhibition of motoneurones in the spinal cord of the cat. J Physiol 226:805-823. CrossRef Medline

Jean-Xavier C, Pflieger JF, Liabeuf S, Vinay L (2006) Inhibitory postsynaptic potentials in lumbar motoneurons remain depolarizing after neonatal spinal cord transection in the rat. J Neurophysiol 96:2274-2281. CrossRef Medline

Jean-Xavier C, Mentis GZ, O’Donovan MJ, Cattaert D, Vinay L (2007) Dual personality of GABA/glycine-mediated depolarizations in immature spinal cord. Proc Natl Acad Sci U S A 104:11477-11482. CrossRef Medline

Jiang Z, Carlin KP, Brownstone RM (1999) An in vitro functionally mature mouse spinal cord preparation for the study of spinal motor networks. Brain Res 816:493-499. CrossRef Medline

Katz R (1999) Presynaptic inhibition in humans: a comparison between normal and spastic patients. J Physiol Paris 93:379-385. CrossRef Medline

Kudo N, Yamada T (1987) Morphological and physiological studies of development of the monosynaptic reflex pathway in the rat lumbar spinal cord. J Physiol 389:441-459. CrossRef Medline

Lance JW (1980) The control of muscle tone, reflexes, and movement: Robert Wartenberg lecture. Neurology 30:1303-1313. CrossRef Medline

Lev-Tov A, Pinco M (1992) In vitro studies of prolonged synaptic depression in the neonatal rat spinal cord. J Physiol 447:149-169. CrossRef Medline

Li Y, Gorassini MA, Bennett DJ (2004) Role of persistent sodium and calcium currents in motoneuron firing and spasticity in chronic spinal rats. J Neurophysiol 91:767-783. CrossRef Medline

Mazzocchio R, Rossi A (1997) Involvement of spinal recurrent inhibition in spasticity: further insight into the regulation of Renshaw cell activity. Brain 120:991-1003. CrossRef Medline
Morita H, Crone C, Christenhuis D, Petersen NT, Nielsen JB (2001) Modulation of presynaptic inhibition and disynaptic reciprocal Ia inhibition during voluntary movement in spasticity. Brain 124:826-837. CrossRef Medline

Nicolopoulos-Stournaras S, Iles JF (1983) Motor neuron columns in the lumbar spinal cord of the rat. J Comp Neurol 217:75-85. CrossRef Medline

Ostroumov A, Simonetti M, Nistri A (2011) Cystic fibrosis transmembrane conductance regulator modulates synaptic chloride homeostasis in motoneurons of the rat spinal cord during neonatal development. Dev Neurobiol 71:253-268. CrossRef Medline

Prescott SA, Sejnowski TJ, De Koninck Y (2006) Reduction of anion reversal potential subverts the inhibitory control of firing rate in spinal lamina I neurons: towards a biophysical basis for neuropathic pain. Mol Pain 2:32. CrossRef Medline

Saadi RA, He K, Hartnett KA, Kandler K, Hershfinkel M, Aizenman E (2012) SNARE-dependent upregulation of potassium chloride co-transporter 2 activity after metabotropic zinc receptor activation in rat cortical neurons in vitro. Neuroscience 210:38-46. CrossRef Medline

Schrøder HD, Danscher G, Jo SM, Su H (2000) Zinc-enriched boutons in rat spinal cord. Brain Res 868:119-122. CrossRef Medline

Sonner PM, Ladle DR (2013) Early postnatal development of GABAergic presynaptic inhibition of Ia proprioceptive afferent connections in mouse spinal cord. J Neurophysiol 109:2118-2128. CrossRef Medline

Stein V, Nicoll RA (2003) GABA generates excitement. Neuron 37:375-378. CrossRef Medline

Stil A, Jean-Xavier C, Liabeuf S, Brocard C, Delpire E, Vinay L, Viemari JC (2011) Contribution of the potassium-chloride co-transporter KCC2 to the modulation of lumbar spinal networks in mice. Eur J Neurosci 33: 1212-1222. CrossRef Medline

Talpalar AE, Endo T, Löw P, Borgius L, Hägglund M, Dougherty KJ, Ryge J, Hnasko TS, Kiehn O (2011) Identification of minimal neuronal networks involved in flexor-extensor alternation in the mammalian spinal cord. Neuron 71:1071-1084. CrossRef Medline

Uvarov P, Ludwig A, Markkanen M, Pruunsild P, Kaila K, Delpire E, Timmusk T, Rivera C, Airaksinen MS (2007) A novel N-terminal isoform of the neuron-specific K-Cl cotransporter KCC2. J Biol Chem 282:3057030576. CrossRef Medline

Uvarov P, Ludwig A, Markkanen M, Soni S, Hübner CA, Rivera C, Airaksinen MS (2009) Coexpression and heteromerization of two neuronal K-Cl cotransporter isoforms in neonatal brain. J Biol Chem 284:13696-13704. CrossRef Medline

van den Pol AN, Obrietan K, Chen G (1996) Excitatory actions of GABA after neuronal trauma. J Neurosci 16:4283-4292. Medline

Wallis DI, Wu J (1992) FAST and SLOW ipsilateral and contralateral spinal reflexes in the neonate rat are modulated by $5-\mathrm{HT}$. Gen Pharmacol 23: 1035-1044. CrossRef Medline

Wang Y, Me X, Zhang L, Lv G (2011) Supplement moderate zinc as an effective treatment for spinal cord injury. Med Hypotheses 77:589-590. CrossRef Medline

Wang Z, Danscher G, Mook Jo S, Shi Y, Daa Schrøder H (2001) Retrograde tracing of zinc-enriched (ZEN) neuronal somata in rat spinal cord. Brain Res 900:80-87. CrossRef Medline

Wang Z, Li L, Goulding M, Frank E (2008) Early postnatal development of reciprocal Ia inhibition in the murine spinal cord. J Neurophysiol 100: 185-196. CrossRef Medline

Woo NS, Lu J, England R, McClellan R, Dufour S, Mount DB, Deutch AY, Lovinger DM, Delpire E (2002) Hyperexcitability and epilepsy associated with disruption of the mouse neuronal-specific $\mathrm{K}-\mathrm{Cl}$ cotransporter gene. Hippocampus 12:258-268. CrossRef Medline 